石油技衔協会誌 第 36 栄 第 6 号 (昭和 46 年 11 月)

JOURNAL OF THE JAPANESE ASSOCIATION OF PETROLEUM TECHNOI.OGISTS

VOL. 36 NO. 6 (Nov., 1971)

原油の可採鉱量評洒に扣ける確率モデル

平 川誠 一**磯 部 治 夫**・尾上哲*

\title{
A Probabilistic Model for Estimation of Oil Reserves
}

\author{
By
}

Seiichi HIRAKawa, Haruo Isobe and Satoru OnOE

\begin{abstract}
This paper presents an actual FORTRAN program of probabilistic model for uncertainty analysis in estimating oil reserves. Factors in this calculation are expressed by triangular probability distribution and uniform random numbers are generated by multiplicative congruence method. The authors consider the shape effect of triangular distribution on estimation of oil reserves. Acknowledgment is given to Dr. Paul J. Root, Associate Professor of Petroleum and Geological Fngineering, University of Oklahoma for his valuable informations concerning with "Decisions under Uncertainty" in carrying out this study.
\end{abstract}

\section{1. 緒言}

探鉱的因子を多分に含んだ油田の開発初期段階におい て，原油の可採鉱量計算に必要な各要素は，一義的に決 められることが難しく，ある幅をもつた情報として得ら れることが多い。このような場合，計算に必要な各要素 を確率分布で表わし，乱数を有効に使用することによっ て, 確率論的手法で可採鉱量を確率分布として求めるこ とができる。これは，いわゆるモンテカルロ法の応用で あるが，筆者らは，この方法で可採鉱量を求めるための プログラムを開発し，具体的な計算例にもとづき若干の 研究をおこなった。本研究は，著者の 1 人，平川が昨年 オクラホマ大学石油工学科に海外出張し, 同大学の油層 工学担当の Dr. Paul J. Root 助教授から, 不確定条件 下での決定論 (Decisions under Uncertainty) に関し ての知識を与えられたことにより，始まったといっても 過言でない。したがって，Dr. Root，それからこの論 文のプログラム作成に協力した藤永好宣氏（東大，工学 部資源開発工学科）に，筆者らは，深謝の意を表わす。

\section{2. 原 理}

原油の可採鉱量 $N$ は, つぎの式から求められる。

$$
N=N_{i} E_{0}-n, \quad N_{i}=\frac{V \phi\left(1-S_{w}\right)}{\beta_{i}}
$$

* 東京大学工学部資源開発工学科

** 束京大学工学部資源開発工学科 (現在出光興産株式会社開発部)
ここに, $N_{i}$ : 原油の総鉱量 $(\mathrm{k} l), V$ : 油層の全容積 $\left(\mathrm{m}^{3}\right)$ 〔簡単にいうと, $V=A \cdot h, A$ : 油層の面積 $\left(\mathrm{m}^{2}\right), h$ : 有効層厚 $(\mathrm{m})], \phi$ : 油層の孔げき率 (小数),$S_{w}$ : 油層 の間げき水飽和率 (小数),$\beta_{i}$ : 開発時以前の 油層内の 圧力および温度における原油の容積係数， $N$ ：原油の可 採鉱量 $(\mathrm{k} l), E_{0}$ ：原油の採収率 (小数), $n$ : 計算時ま での原油の累計産出量 $(\mathrm{k} l)$

もし, この油層が生産開始時以前, すなわち, $n=0$ で，かつ，Nの計算に必要な各要素の值が不確定 (uncertainty)であり，それらをそれぞれ確率変数 (random variable) と見做せる場合に，Nの決定（decision）手 段として，つぎの方法が考えられる。

連続確率変数 $x$ のきには，それがある值をとる確率 $P_{r}$ は, $P_{r}=f(x) d x$ で表わされ, $\int_{-\infty}^{\infty} f(x) d x=1$ が成 り立つ。ここで, $f(x)$ は確率密度関数 (probability density function）でありまた，その不定積分

$$
F(x)=\int_{-\infty}^{x} f(\xi) d \xi
$$

は累積分布関数 (cumulative distribution function) と いら。

いま, 確率密度関数 $f(x)$ を三角形分布 (triangular distribution) であらわし， $x$ の下限值 (lower limit) を $x_{1}$, most likely value (以下, 仮りに最頻值と呼ぶ) を $x_{2}$, 上限值 (upper limit) を $x_{3}$ とし， $x_{1} \leqq x \leqq x_{2}$ および $x_{2} \leqq x \leqq x_{3}$ の範囲では, $f(x)$ が直線的に変化 し，さらに三角形の面積が1になるように考えると， 
$f(x)$ は，つぎの式で表わせる。

$x_{1} \leqq x \leqq x_{2}$ のとき

$$
f(x)=\frac{2\left(x-x_{1}\right)}{\left(x_{3}-x_{1}\right)\left(x_{2}-x_{1}\right)}
$$

$x_{2} \leqq x \leqq x_{3}$ のとき

$$
f(x)=\frac{2\left(x-x_{3}\right)}{\left(x_{3}-x_{1}\right)\left(x_{2}-x_{3}\right)}
$$

したがって累積分布関数は

$x_{1} \leqq x \leqq x_{2}$ のとき

$$
F(x)=\frac{\left(x-x_{1}\right)^{2}}{\left(x_{3}-x_{1}\right)\left(x_{2}-x_{1}\right)}
$$

$x_{2} \leqq x \leqq x_{3}$ のとき

$$
F(x)=1-\frac{\left(x-x_{3}\right)^{2}}{\left(x_{3}-x_{1}\right)\left(x_{3}-x_{2}\right)}
$$

さらにこれを $x$ について解くと

$$
\begin{gathered}
x=x_{1}+\sqrt{F(x)\left(x_{3}-x_{1}\right)\left(x_{2}-x_{1}\right)} \\
\left(0 \leqq F(x) \leqq F\left(x_{2}\right)\right) \\
x=x_{3}-\sqrt{\frac{(1-F(x))\left(x_{3}-x_{1}\right)\left(x_{3}-x_{2}\right)}{(}}\left(F\left(x_{2}\right) \leqq F(x) \leqq 1\right)
\end{gathered}
$$

と表わせる。

$F(x)$ と $x$ は 1 対 1 に対応するから, $F(x)$ を知るこ とによって $x$ を求めることができる。そこで，(0，1)間 の一様乱数のある数值を $F(x)$ の值として, 上式に代入 し， $x$ を計算させ，この操作を沢山の乱数についておこ なら。すなわち，これは確率的要素を含む問題を，乱数 の有効利用によって，処理しようとするのであって，い わゆるモンテカルロ法 (Monte Carlo Method) の応用 である。本論文では, 面積・有効層厚・孔隙率などの各 要素を確率分布で表わし，乱数に応じて，各要素を決定 し，原油の可採鉣量を確率論的に算出しようと考えた。

\section{3. プログラミング}

計算手順は図 1 のフローチャートに示す。さらに，説 明を加えると，

ステップ1 原油の可採鉱量計算に必要な各要素につ いて，下限值・最頻値・上限值の 3 つの 值を 1 組のデータとして読み込ませる。

ステップ 2 これら各要素の上限值と下限值とを用い て，原油の可採鉱量の上限值と下限値と を計算させる。

ステップ 3 下限值と上限値の間を等分して, $m$ 個の 区間に分ける。

ステップ $4 \sim 9$ 乱数を発生させて, 原油の可採鉱量 計算に必要な各要素の大きさ (数值)を 決定させる。

ステップ10 各要素の值を用いて, 可採鉱量を計算さ せる。
図 1 フローチャート

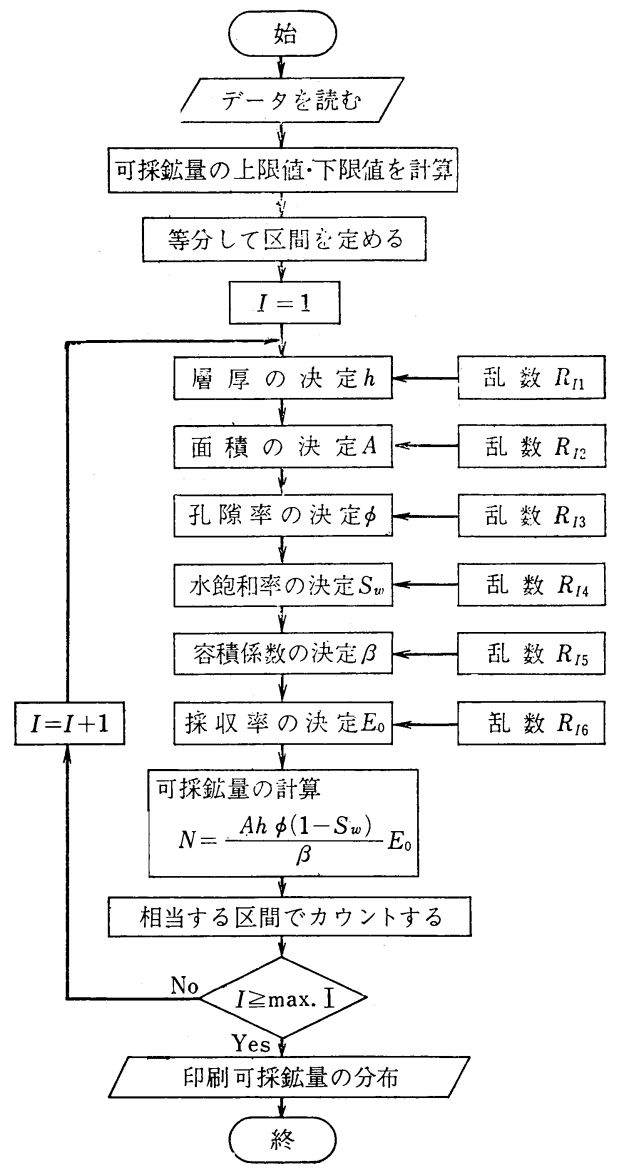

ステップ11 可採鉱量の算出值が，ステップ 3 で等分 したいずれの区間に入るかを判定し，そ こでカウントする。

ステップ12 同じ操作を充分な回数までくり返し行な 5。

つぎに使用した乱数は，(0，1)の一様乱数であり，東京 大学大型計算機センターのライブラリー プログラムの 中の, $37 \mathrm{G} 5 / \mathrm{TC} / \mathrm{RUN1}$ という一様乱数発生プログラム を本研究に使用した。これは伏見正則・藤野浩二両氏の 作成, 山本敦子氏の改訂によるもので, 計算方法（発生 方法）は乗算型合同式法である。すなわち

$$
\begin{aligned}
& X_{n+1}=\lambda X_{n}(\bmod P) \\
& \lambda=5^{11} \\
& P=2^{31}
\end{aligned}
$$

によって，乱数系列 $\left\{X_{n}\right\}$ を定めている。以上のように して，本論文で原油の可採鉱量 $N$ 計算させるために， 図1のフローチャートに対応して開発したプログラムを 表 1 に示す。このほかに図 2 のフローチャートに示す計 
表 1 プ ロ グ ラ ム

\$LIGRARYG5 SEARCH YPJUT3

DIMENSION DRES(1jJI), RES(10), N(1U),II ( IO)

RËAD(5,9UJU) THICKL, THICKM, THICKH,AREAL, AREAV, AREAH,

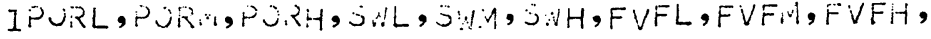
2REFACL, REFACV, REFACH,

9000 FOR VAAT ( 3F15 UU)

1 RESH=THICKH*AREAH JP JP RESM=THICKM *AREA V*PUP

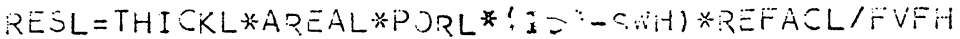
RESP = (RESH-RESL )/IU.?

$R E S(1)=R E S L+R E S P$

DO $12 \mathrm{I}=2,10$

$R E S(I)=R E S(I-I)+R E S P$

12 CONTINUE

D) 13 I $=1,1 \mathrm{~J}$

$N(I)=0$

13 CONTINUE

MRITEDS,9200)

9200 FORMAT (1HI,3JX, IUHINDJT DATA!

IR IOTE $(6,921.0)$

9210 FURMATPIH, IUX, 12HLOUER LIUITT, ЭX,17HMOST LIKELY VALUE, 3X, 112 HUPPER LI:ITT)

WRITE $(6,9220)$ THICKL, THICKY, THICKH

9220 FURMAT (IH, $2 X, 5 H T H I C K, 3 X, E 15.7,5 X, E 15.7,5 X, E 15.7)$ NRITE $(6,9230)$ ARËAL, AREAM, AREAH

9230 FORMAT (IH, $2 X, 4 H A R E A, 4 X, E 15.7,5 X, E 15.7,5 X, E 15.7)$ WRITE $(6,9240)$ PORL, DOR.

9240 FURMAT(IH, $\left.2 X, 3 H F H^{2}, 56, E 15.7,5 X, E 15.7,5 X, E 15.7\right)$

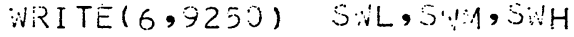

9250 FORMAT ( IH, $2 X, 2 H$ SN, $5 X, E 15.7,5 X, E 15.7,5 X, E 15.7)$ VRITE $(6,9260)$ FVFL, =VFM,FVFH

9250 FORYAT(IH, 2X,3HFVF, $X, E 15.7,5 X, E 15.7,5 X, E 1 j .7)$ WRITE $6,927 U)$ REFACL, REFACM, REFACH

9270 FORMAT(IH, 2X, 5HREFAC, 3X,E15.7, $5 X, E 15.7,5 X, E 15.7)$ WRITE $(6,3230)$ RESL, PESH, RES: , RESP

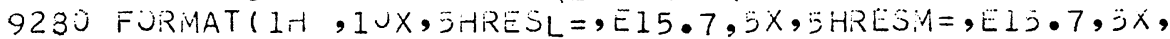

15 SHRESH $=, E 15 \cdot 7,5 X, 5 H R E J P=$, $\Xi 15.71$

D) $8 I=1,1 j$

$I I(I)=I$

8 CONTINUE

DO $1111 \mathrm{~J}=1,10 \mathrm{j}$

DRES $(J)=0.0$

1111 CONTINUE

$I J K=0$

$I R=1234567$

2 CALL RUNI(IR, R)

$Y F L=R$

THICK =THICKL+SQRT (YFL*(THICKM-JHICKL)*(THICKH-THICKL)

IF(THICK.LE•THICKM) SO TO 10 
THICK $=$ THICKH-SURT ( (1.j-YFL $) *(T H I C K H-T H I C K L) *(T H I C K H-T H I C K H))$

10 CALL RUNI(IR,R)

$Y F L=R$

AREA = AREAL+SQRT (YFL* (AR ËAM-APEAL)* (AREAH-AREAL))

IF(AREA.LE.AREAM) GO TO 20

AREA $\rightarrow A R E A H-S Q R T((1 \bullet U-Y F L) *(A R E A H-A R E A L) *(A R E A H-A R E A 4))$

20 CALL RUNI(IR,R)

YFL $=R$

$P O R=P O R L+S Q R I(Y F L *(P \cap R M-P J R L) *(P O R H-P O R L))$

IF (POR.LE.PORM) GU TO $3 U$

$P O R=P O R H-S Q R T((1, j-Y C L) *(P O R H-P O R L) *(P O R H-P O R, M))$

30 CALL RUNI(IR,R)

$Y F L=R$

$S W=S W L+S Q R T(Y F L *(S N M-S W L) *(S: H-S: L))$

IF(SN.LE.SWM) GO TO $4 \mathrm{~J}$

$S W=S W H-S Q R T((1 \bullet U-Y F L) *(S: H H-S: L L) *(S: H H-S W$ Niv $))$

40 CALL RUNI(IR,R)

YFL $=R$

$F V F=F V F L+S Q R T(Y F L *(F V F M-F V F L) *(F V F i-F V F L))$

IF (FVF.LE.FVFM) GO TO 5U

$F V F=F V F H-S Q R T((1, U-Y F L) *(F V F H-F V F L) *(F V F H-F V F M))$

50 CALL RUNI(IR,R)

$Y F L=R$

REFAC=REFACL+SQRT (YFL*( REFACM-REFACL)*(REFACH-REFACL) )

IF (REFAC.LE.REFACIM) GO TO 60

REFAC=REFACH-SQRT ( (1.0-YFL)* REFACH-REFACL)*(REFACH-REFACIM))

60 RESERV $=$ THICK*AREA*POR*(1.0-S!)*REFAC/FVF

$I J K=I J K+I$

DRES $(I J K)=R E S E R V$

IF(RESERV.GE.RES(1)) GO TO 70

$N(1)=N(1)+1$

GO TO 90

70 IF(RESERV.GE.RES(2)) GO TO 71

$N(2)=N(2)+1$

GO TO 90

71 IF(RESERV.GE•RES(3)) GU TO $7 ?$

$N(3)=N(3)+1$

GO TO 90

72 IF(RESERV.GE.RES(4)) GO TO 73 $N(4)=N(4)+1$

GO TO 90

73 IF (RESERV.GE.RES(5)) GO TO 74 $N(5)=N(5)+1$

GO TO 90

74 IF (RESERV.GE・RES(6)) GO TO 75 $N(6)=N(6)+1$

GO TO 90

75 IF(RESERV.GE・RES(7)) GO 1076

$N(7)=N(7)+1$

GO TO 90 


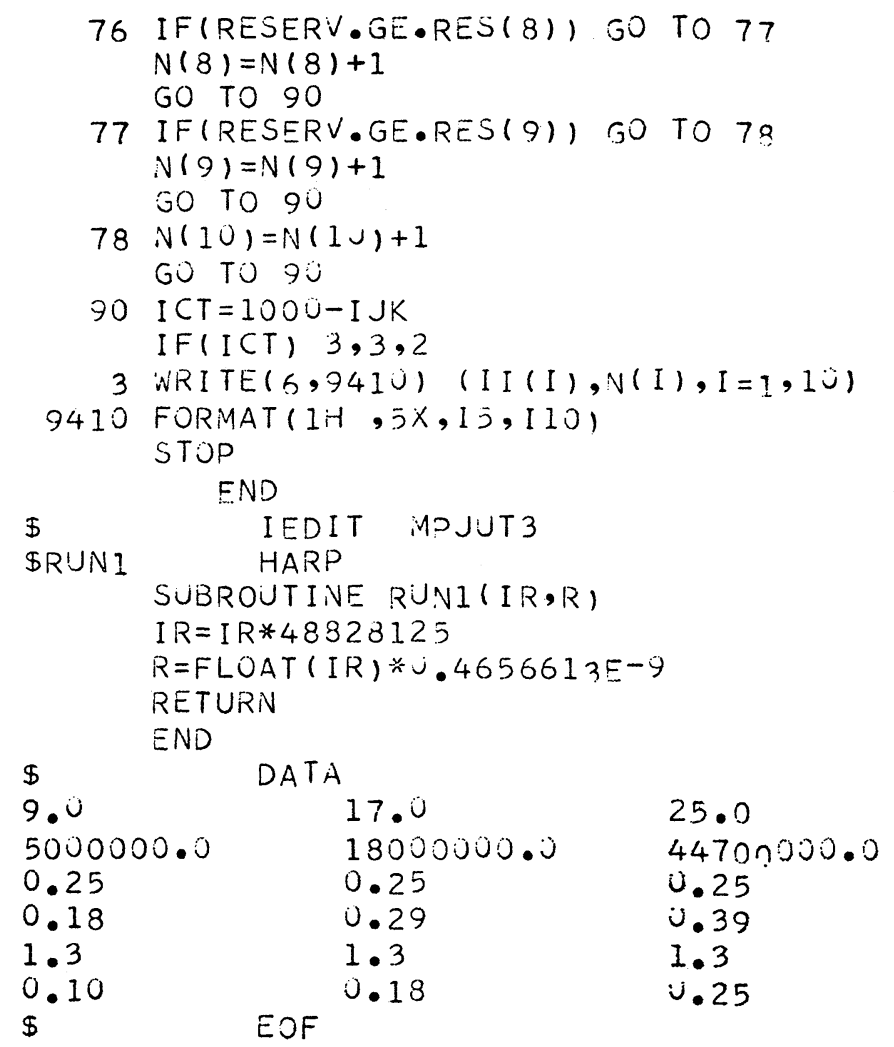

算方法も試みたが，これは本論文では参考資料として提 示するにとどめて扔く(注)。

（注）乱数の使用法

本文のフローチャートで示した乱数の使用法は, 原油 の可採鉱量の計算に必要な各要素の決定にあたり, 別々 の乱数使用の方法である。それとは別に, 図 2 のフロー チャートでは, 1 つの乱数のみを発生させ, その乱数で すべての要素を決定しょうと考光てみた。これは理論的 に多少不自然なやり方であるが, 技術的に満足しらる結 果が得られれば，時間が短縮できるので有効な試みと思 5。本文に示した計算例に打いては満足な結果は得られ ているが, その所要時間は 3 秒で, 本文の方法の 4 秒に 対して 1 秒の短縮のみにとどまった。

\section{4. 計 算 例}

探鉱的因子を多分に含んだ油田の開発初期段階におい て, 原油の可採鉱量計算に必要な各要素は, 一義的に決 められることが難しく, ある幅をもった情報として得ら れることが多い。例光ば計算対象面積として，地震探鉱 結果からの地下構造図にもとづく值，それから何らかの 情報による油一水界面を推定考慮した值，さらに対象油
田近傍の既存開発油田の情報など加えて, 上限値・最頻 值・下限值を推測でさる場合がある。また有効層厚・孔 隙率・水飽和率の各要素も, 各種検層結果およびュア試 験結果を総合判断して, ある幅をもった数值としての情 報が兄られることがある。さらに，採収率は水押しェネ ルギーの有無, および強弱, さらに油層岩の性質などに よって，上限および下限をもつ数值として期待されるこ とがある。いま，ここで提示したプログラムにより，若 干の計算をおこなうために，ある実在油田 (油層) の開 発初期段階でえられた情報にもとづき作成した資料（表 2)を使用することにした。

さて, 前述したフローチャートに示す繰返し計算の回 数が少ないと, 算出結果に乱数の配列の仕方の影響が出 てしまう。そこで最初に計算試行回数と可採鉱量の確率 分布との関係を調べ，計算試行回数の決定を試みた。表 こ 2 の諸資料では, 700 回以上の試行をやれば充分であ ることが表 3 より知られる。700回の試行計算の結果, 図 3 (10等分区間した結果), 図 4 (30等分区間) に示すよ らな結果が得られた。この両図から知れるように, 原油 の可採鉱量が，700 800 万 $\mathrm{k} l$ である確率が最も高いと いえる。油田の開発進行により情報が増加すると, 計算 
図 2 フローチャート（参考資料）

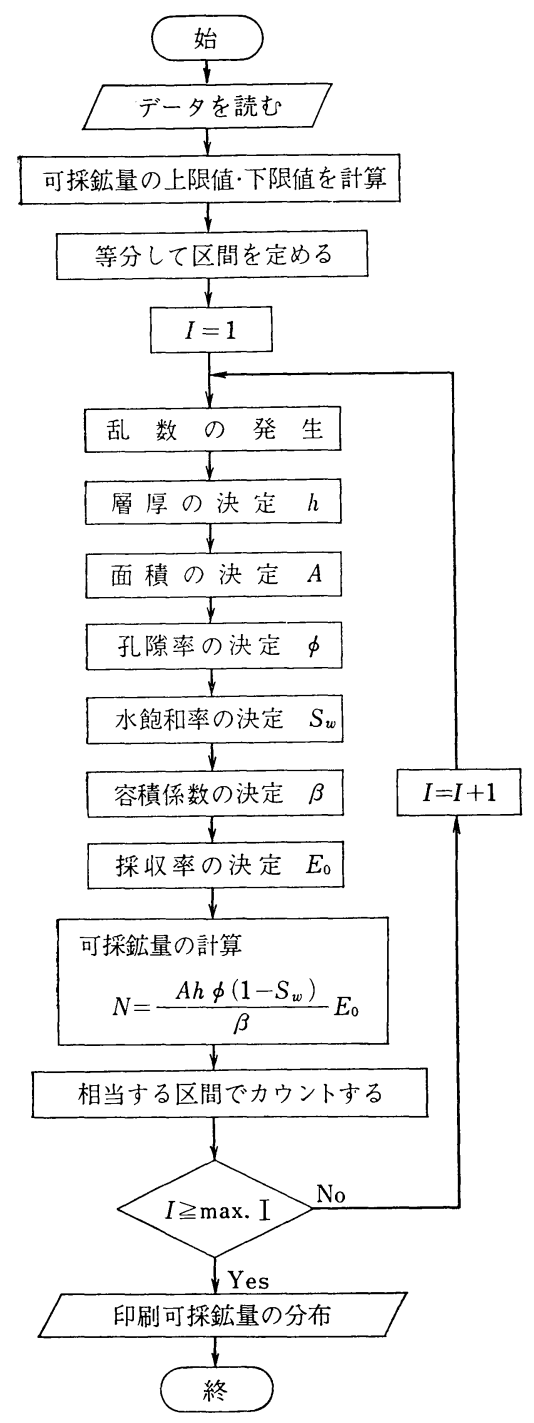

表 2 計算例として用いた原油可採鉱量 算出の各要素

\begin{tabular}{l|l|c|c|}
\hline & 下限 值 & 最 頻 值 & 上限 值 \\
\hline 油層面積 $\left(\mathrm{km}^{2}\right)$ & 5.0 & 18.0 & 44.7 \\
有効 層 厚 $(\mathrm{m})$ & 9.0 & 17.0 & 25.0 \\
油層の 孔 隙率 & 0.25 & 0.25 & 0.25 \\
油層の水飽和率 & 0.18 & 0.29 & 0.39 \\
原油の容積係数 & 1.3 & 1.3 & 1.3 \\
原油の 採収率 & 0.10 & 0.18 & 0.25 \\
\hline
\end{tabular}

に必要な各要素のうち, 1 つの要素の上限値, 下限値の

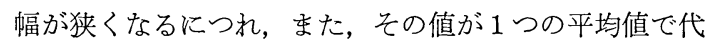
表できるにつれて，モンテカルロ法応用による可採鉱量
表 3 計算試行回数之可採鉱量の 確率 $(\%)$ との関係

\begin{tabular}{|c|c|c|c|c|c|c|}
\hline $\begin{array}{l}\text { 可採金 } \\
\text { ( } \\
\text { 試行 } \\
\text { 回数 }\end{array}$ & $\begin{array}{c}5.3 \\
i \\
48.8\end{array}$ & $\begin{array}{l}48.8 \\
92.3\end{array}$ & $\begin{array}{c}92.3 \\
2 \\
135.8\end{array}$ & $\begin{array}{c}135.8 \\
? \\
179.3\end{array}$ & $\begin{array}{c}179.3 \\
2 \\
222.3\end{array}$ & $\begin{array}{c}222.3 \\
\hat{\imath} \\
266.3\end{array}$ \\
\hline 100 & 17 & 34 & 29 & 11 & 7 & 0 \\
\hline 200 & 13 & 36 & 30 & 15 & 5 & 1 \\
\hline 300 & 14 & 38 & 29 & 13 & 4 & 1 \\
\hline 400 & 14 & 39 & 29 & 13 & 4 & 1 \\
\hline 500 & 14 & 41 & 27 & 13 & 4 & 1 \\
\hline 600 & 15 & 41 & 27 & 12 & 4 & 1 \\
\hline 700 & 15 & 42 & 27 & 12 & 4 & 0 \\
\hline 800 & 15 & 42 & 27 & 12 & 4 & 0 \\
\hline 900 & 15 & 42 & 27 & 12 & 4 & 0 \\
\hline 1,000 & 15 & 43 & 26 & 12 & 4 & 0 \\
\hline
\end{tabular}

図 3 原油の可採鉱量の確率分布 (10等分区間の場合)

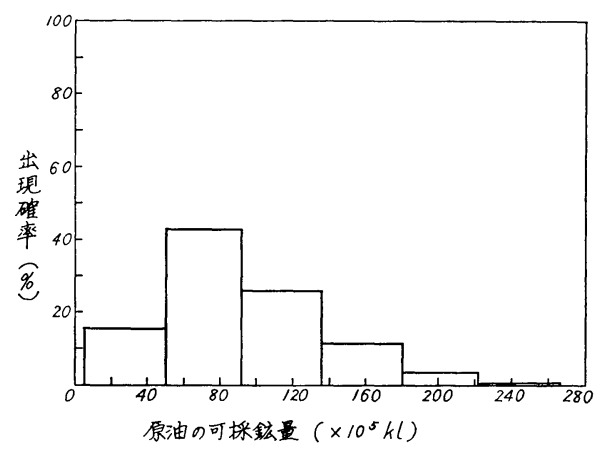

図4 原油の可採鉣量の確率分布 （30等分区間の場合）

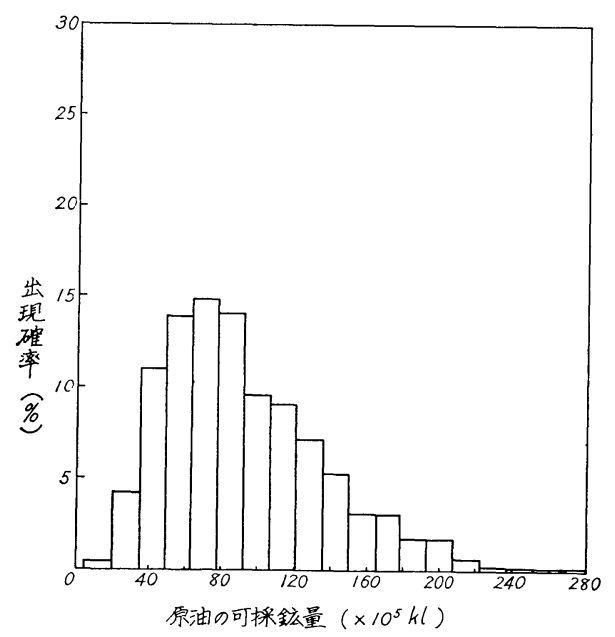


図 5 有効層厚の確率分布の変化と算出結果の変化との関係
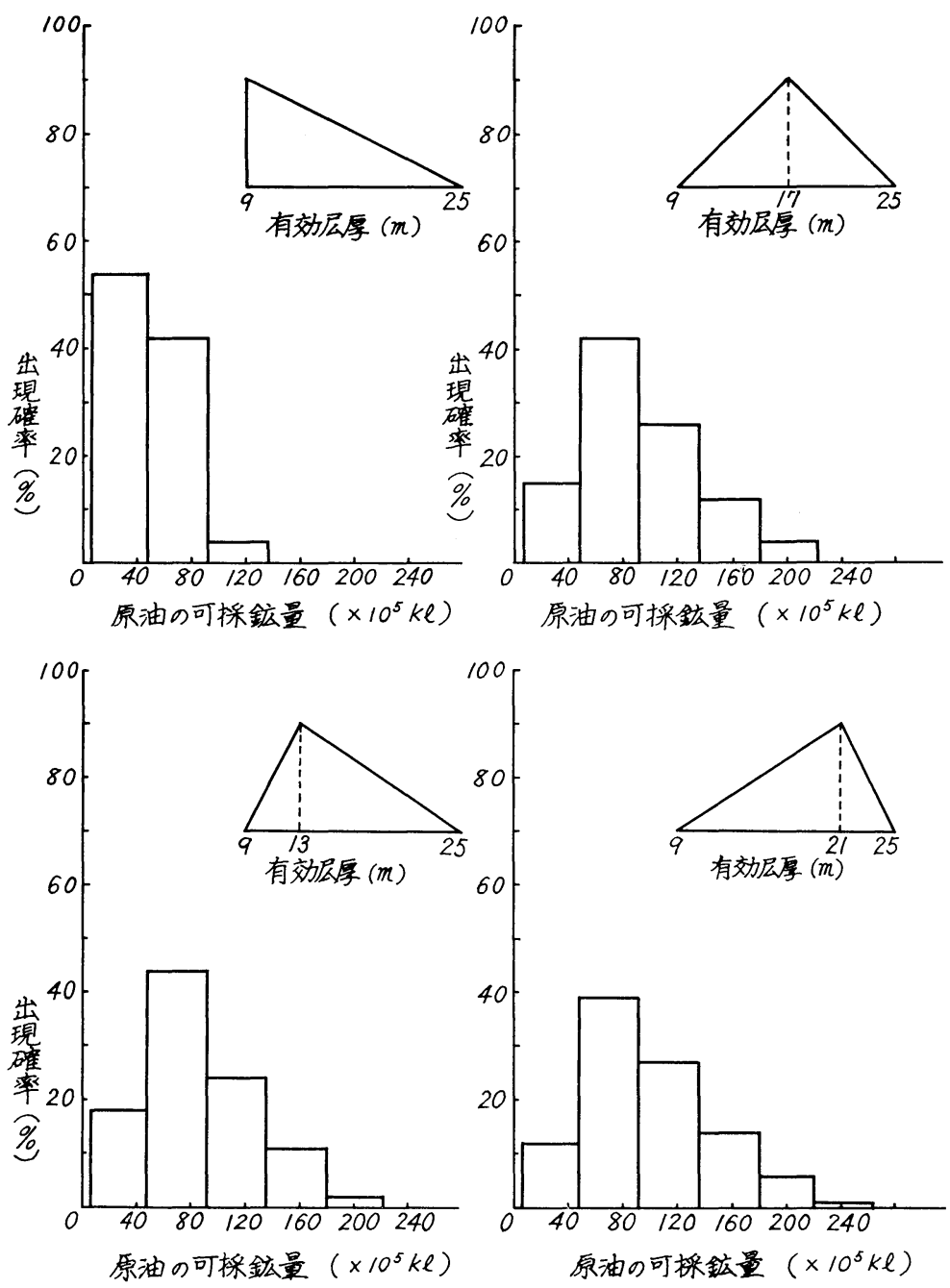

の值の上限值および下限值の羑が小さくなる。

つぎに，可採鉱量計算に必要な各要素の確率分布と，

算出された可採鉣量の確率分布との間の相関関係を調べ た。その1例として, 有効層厚の最頻值を変化させて, 可採鉱量を計算した結果を図 5 に示す。最頻値が下限値 に等しくなるよらな極端な場合は別として，上限値と下 限值の間で最頻值が多少変化しても, 結果に大きな影響 はないことが知れる。この例示結果から推測するに, 可 採鉱量の算出值が，各要素を表現する確率分布の形状に 大きく影響されないと思われるので，ここに採用した簡 便な三角形分布は，この種の技術計算に有効なものであ ると考觉る。

\section{5. 結 語}

油田の開発初期段階において, 原油の可採鉱量計算に 必要な各要素が一義的に求められず，ある幅をもった情 報として得られるよらな場合に, モンテカルロ法を応用 しての推算方法をプログラムし, 計算研究に備えた。こ の開発したプログラムを利用し，ある種の研究をおこな っている。そのらちの若干を計算例として, ここに提示 した。すなわち, この計算に先立って, 乱数の配列の仕 方に影響されないまで, 繰り返し計算をおこなう必要性 にふれ,つづいて, 可採鉱量計算に必要な各要素の確率 分布の形状が，可採鉱量の算出結果に大きく影響しない ことを計算から明らかにした。 